\title{
Literatura infantil, relações de poder-saber e posições de sujeito no currículo do primeiro ano
}

\author{
Maria Carolina da Silva Caldeira \\ Universidade Federal de Minas Gerais \\ Marlucy Alves Paraíso \\ Universidade Federal de Minas Gerais
}

\section{Resumo}

Este artigo analisa, com base na perspectiva foucaultiana, os modos como a literatura aparece no currículo de uma turma de primeiro ano do ensino fundamental de Belo Horizonte/MG. Durante a investigação - que usou técnicas etnográficas de pesquisa e análise de discurso - foram constatados três usos para a literatura: introdução de algum conteúdo; ensino dos processos de interpretação de textos; trabalho com a diversidade cultural. Argumenta-se que, ao se trabalhar a literatura dessas três formas, ao mesmo tempo que se alcançam os objetivos estabelecidos, abrem-se possibilidades para que modos de ser menos disciplinados e mais transgressores apareçam nesse currículo. Palavras-chave: Currículo. Literatura infantil. Relações de poder-saber.

\section{Children's Literature, relations of power-knowledge and positions of subject the individual in the curriculum of the first year}

\section{Abstract}

This article analyzes, on the basis of Foucault's perspective, the ways in which literature appears in the curriculum of a first year class of Elementary school of Belo Horizonte/MG. Throughout the investigation - in which we used techniques of ethnographic research with discourse analysis of Foucault's inspiration - we noticed that there was in the investigated curriculum three main uses for literature: introduction of some school content; teaching of interpretation of texts; work with cultural diversity. It is argued that, when working the literature of three ways at the same time that achieve the established objectives, open up possibilities for ways of being less disciplined and more offenders appear in this curriculum.

Keywords: Curriculum. Children's literature. Relations of power-knowledge. 


\section{La literatura infantil, las relaciones de poder - saber y sujetos posicio- nes en el currículo del primer grado}

\section{Resumen}

Este artículo analiza, a partir de la perspectiva de Foucault, los usos que se hacen de la literatura en el currículo de una clase de primer año de la escuela primaria da ciudad de Belo Horizonte/MG. Durante la investigación - que utiliza técnicas etnográficas de la investigación y el análisis del discurso - se encontraron tres usos para la literatura: introducción de algún contenido; enseñanza de la interpretación de los procesos de textos; trabajar con la diversidad cultural. El argumento desarrollado es que cuando se trabaja la literatura de tres maneras a la vez que alcancen los objetivos fijados, se abren posibilidades de formas de ser delincuentes menos disciplinados y más aparecen en este currículo.

Palabras clave: Currículo. Literatura infantil. Relaciones de poder-saber.

Fantasia, romance, diversão, crítica social, utopia, alienação, fabulação, mistério, magia, diversão: esses são alguns dos sentidos que a literatura tem no Ocidente na contemporaneidade. Marcada pelos jogos de linguagem e pela relação que estabelece com a verdade, a literatura é entendida de diferentes modos em nossa sociedade. Por um lado, ela é apresentada como artefato envolvido em relações de poder-saber bem específicas. A literatura é considerada uma produção marcada pelas características, interesses e demandas de determinada época. Nesse sentido, ela pode ser vista como algo que "[...] pertence à mesma trama que todas as outras formas culturais, a todas as outras manifestações do pensamento de uma época" (FOUCAULT, 1991, p. 84). Por outro lado, uma importante marca constantemente atribuída à literatura é fazer sair do lugar, sonhar, desviar. Nesse sentido, a literatura ultrapassa as relações de poder-saber engendradas, sendo caracterizada também por trangredi-las. É possível então, pensar a literatura como "[...] uma linguagem transgressiva, mortal, repetitiva, reduplicada" (FOUCAULT, 2001, p. 154). Isso ocorre porque, pelos jogos de linguagem que ela proporciona, é possível escapar ao que está estabelecido e criar outras relações de poder. Como afirma Larossa (1998, p. 13), ao se referir à literatura como possibilidade de 
formação, "[...] sua única virtude é sua infinita capacidade para a interrupção, para o desvio".

Por sua relação com o saber e com o poder e, ao mesmo tempo, pela possibilidade de rompimento com essas relações de poder e de saber já instituídas, a literatura está envolvida também com a produção de diferentes modos de ser e estar no mundo. Nela, são disponibilizados processos de subjetivação, entendidos como "[...] as diversas maneiras pelas quais os indivíduos ou as coletividades se constituem como sujeitos" (DELEUZE, 1992, p. 217). A literatura disponibiliza processos de subjetivação porque possibilita escapes em relação aos poderes e saberes constituídos. Afinal, os processos de subjetivação "[...] só valem na medida em que, quando acontecem, escapam tanto aos saberes constituídos como aos poderes dominantes", mesmo que, logo em seguida, novos poderes sejam ativados. Contudo, "[... ] no espaço da literatura não há ruptura absoluta, transgressão de uma vez por todas" (MACHADO, 2001 , p. 44 e 60). A partir do momento em que se rompe com o estabelecido, novos limites são criados, já que "[...] há cumplicidade entre o limite e a transgressão, a lei e a violação da lei".

Ao investigar um currículo de uma turma de primeiro ano do ensino 168 fundamental de uma escola da Rede Municipal de Belo Horizonte (RMBH) foi possível verificar a presença da literatura, particularmente daquela que vem sendo nomeada de literatura infantil, isto é, aquela que tem como público-alvo as crianças ${ }^{1}$. Foi possível perceber também como a literatura era, ao mesmo tempo, espaço de reiteração das normas e de fuga temporária dessas normas. No currículo investigado, a literatura estava presente no momento de "leitura e contação de histórias" que ocorria na turma praticamente em todos os dias.

A pesquisa foi realizada durante o ano letivo de 2013 e fez uso de técnicas etnográficas pós-modernas, para a produção das informações, e da análise de discurso de inspiração foucaultiana para análise das informações produzidas. Nas observações, foram acompanhados/as os/as 26 alunos/as da turma e a professora, durante as aulas, atividades coletivas (como jogos, excursões, apresentações), recreio e momentos de planejamento da docente. As informações foram registradas por meio de diário de campo, fotografias de alguns momentos e coleta das atividades realizadas em sala de aula.

A etnografia pós-moderna refere-se a um conjunto de estudos que têm procurado afastar-se tanto das perspectivas clássicas e estruturalistas da 
antropologia, como de perspectivas hermenêuticas (CALDEIRA, 1988). Esse afastamento se deve à consideração de que a etnografia clássica tinha um caráter colonial, realizando hierarquizações entre a cultura do/a etnógrafo/a e dos/as informantes das pesquisas e produzindo verdades que buscavam pela estrutura que caracterizava o ser humano para além das diversidades culturais (CLIFFORD, 2008). Na perspectiva da antropologia hermenêutica, por sua vez, buscava-se por um "significado profundo" que poderia ser acessado por meio de uma "descrição densa" (GEERTZ, 1997). A perspectiva etnográfica pós-moderna parte do "[...] caráter seletivo e parcial da 'verdade' antropológica" (CALDEIRA, 1988, p. 147) e do princípio de que os textos etnográficos produzidos estão envolvidos em relações de poder, que, por sua vez, atuam na produção de verdades sobre os grupos culturais pesquisados.

A análise de discurso de inspiração foucaultiana realizada com base nos dados produzidos também parte do pressuposto de que as práticas desenvolvidas em sala de aula estão envolvidas em relações de poder. Inspiradas por essa perspectiva, procurou-se compreender os discursos que ali circulavam, as relações de poder estabelecidos, as estratégias, técnicas e táticas desenvolvidas pela professora e pelos/as alunos/as (FOUCAULT, 2000). Buscou-se investigar como a literatura estava presente na sala de aula, articulando diferentes discursos, colocando em ação diferentes relações de poder e demandando diversas e conflitantes posições de sujeito.

Durante a investigação, foram lidos em sala de aula 41 livros literários, sendo que alguns deles tinham mais de uma história e eram lidos por mais de um dia. Nos momentos de leitura, a professora selecionava um livro de literatura infantil e lia as histórias para as crianças, que participavam ativamente, interpretando, discutindo, expressando suas opiniões e avaliando as narrativas contadas. Ocasionalmente, alguma criança também levava um de seus livros para a sala de aula e a docente contava a história ali presente.

São esses diferentes momentos em que a literatura infantil se fazia presente no currículo investigado que serão analisados neste artigo cujo objetivo consiste em analisar os efeitos do uso da literatura infantil no currículo investigado em sua articulação com o dispositivo da infantilidade e da antecipação da alfabetização. Para isso, pretende-se mostrar os usos que são feitos da literatura infantil nesse currículo, os saberes e as relações de poder priorizadas e as posições de sujeito disponibilizadas. 
A literatura infantil possibilitava articular, no currículo investigado, o dispositivo de infantilidade ao dispositivo de antecipação da alfabetização. Dispositivo é entendido aqui com base em Foucault (2000, p. 244) como "[...] um conjunto decididamente heterogêneo que engloba discursos, instituições, organizações arquitetônicas, decisões regulamentares, leis, medidas administrativas, enunciados científicos, proposições filosóficas, morais, filantrópicas" (FOUCAULT, 2000, p. 244), e que está envolvido na produção de modos de subjetivação. O dispositivo de antecipação da alfabetização, por sua vez, refere-se aos elementos heterogêneos que têm sido utilizados para demandar e justificar que a alfabetização das crianças aconteça o quanto antes, preferencialmente no primeiro ano do ensino fundamental nas escolas públicas brasileiras². Já o dispositivo de infantilidade concerne ao conjunto de elementos que possibilitou, a partir do século XVI, que os seres, nos anos iniciais de vida, passassem a ser identificados como crianças. As características que distinguem os/as adultos/as das crianças foram, na perspectiva aqui adotada, construídas peça por peça por esse dispositivo, que agiv e continua agindo no sentido de diferenciar e de distinguir adultos/as de crianças.

A literatura infantil é um dos elementos do dispositivo de infantilidade.

170 Afinal, só a partir do momento em que esse dispositivo começou a operar foi possível pensar em uma literatura específica para esse público. Como afirma Zilberman (2009, p. 15, grifo da autora), "[...] os primeiros livros para crianças foram produzidos ao final do século XVII e durante o século XVIII [... $]^{\prime \prime}$, pois antes disso "[...] não se escrevia para elas, porque não existia a 'infância'.

A literatura infantil e a escola também "[...] têm suas histórias intimamente entrelaçadas" (SILVEIRA, 2005, p. 105), seja porque uma das funções da escola é ensinar a ler esses textos, seja porque a escola é uma das principais compradoras desse gênero textual (ZILBERMAN, 2009). No momento em que o ensino fundamental se expande e no qual atua o dispositivo da antecipação da alfabetização, a literatura infantil é convocada a assumir um papel importante nesse processo. $\bigcirc$ trabalho com literatura no currículo do primeiro ano do ensino fundamental serve tanto para garantir que as crianças se alfabetizem e letrem, como para proporcionar a manutenção de certas características infantis, tais como a imaginação, a criatividade e a fantasia.

Por ser tanto um recurso para letrar e alfabetizar, como um elemento que serve para manutenção de determinadas características comumente associadas às crianças, considera-se que a literatura funciona como um articulador 
do dispositivo de infantilidade e da antecipação da alfabetização no currículo investigado. Afinal, "[...] a literatura não é senão o efeito de um certo dispositivo de poder que atravessa no Ocidente toda a economia dos discursos e as estratégias do verdadeiro" (FOUCAULT, 2006, p. 221). Ela está, portanto, articulada a esses dois dispositivos de poder que operavam no currículo investigado.

Durante a pesquisa, foi possível perceber três usos principais da literatura em sala de aula. $O$ primeiro deles refere-se ao uso dos livros literários para introdução de algum conteúdo escolar. $\bigcirc$ segundo refere-se à articulação com os processos de leitura e interpretação de textos, o que vem sendo nomeado de letramento literário (PAULINO, 2010; COSSON, 2014). O terceiro se articula ao trabalho com a diversidade cultural, demanda cada vez mais presente em currículos de diferentes níveis de ensino. Tendo em vista que a literatura é, ao mesmo tempo, engendramento de certas relações de poder-saber e transgressão, argumenta-se que, no currículo investigado, ao se trabalhar a literatura dessas três formas, ao mesmo tempo que se alcançam os objetivos didáticos estabelecidos, abrem-se as portas para que modos de ser aluno/a menos disciplinados/as apareçam nesse currículo. O caráter ambíguo, múltiplo e multifacetado da literatura - mesmo quando ela é escolarizada - faz com que outras possibilidades de viver a infância sejam inseridas nesse currículo. Para desenvolvimento desse argumento, este artigo está dividido em três partes. Cada uma delas mostra um dos usos feitos da literatura na turma investigada.

\section{Apreciação e interpretação: o discurso do letramento literário na sala de aula}

Ouvir histórias no currículo investigado era uma prática quase diária. Ela só deixava de ser realizada quando a rotina era reorganizada em função de eventos específicos, como avaliações (DIÁRIO DE CAMPO, 2013), comemorações escolares, como a festa do folclore (DIÁRIO DE CAMPO, 2013) ou eventos esportivos, como as Olimpíadas (DIÁRIO DE CAMPO, 2013). Excetuando esses momentos, diariamente a professora selecionava algum livro e o levava para a sala de aula. $\bigcirc$ objetivo buscado com esse trabalho era ensinar as crianças a apreciar histórias e interpretá-las. Nesses momentos, operava o discurso do letramento literário, que tem como propósito na escola tanto ensinar a apreciar os textos literários como uma experiência estética, 
aprendendo que a leitura literária "[... ] é associada à reflexão e à imaginação, quando estimula nossa percepção a romper com o automatismo da rotina cotidiana" (PAIVA, PAULINO, PASSOS, 2006, p. 25), como contribuir para "[...] o desenvolvimento de habilidades de compreensão, interpretação e construção de sentidos de textos" (SOARES, 2010, p. 16). Dessa forma, a leitura literária era escolarizada, visando tanto à construção de habilidades de leitura e interpretação, como a fruição e o prazer.

Um exemplo de livro literário trabalhado com esse objetivo refere-se à história "Quer brincar de pique-esconde" (BRAGANÇA; CARPANEDA, 2008). Para contá-la, a professora inicia uma conversa com a turma sobre os procedimentos necessários para a escuta da história. Ela lembra a necessidade de ficar calados e atentos para ouvir a história. Ressalta importância de "[...] abrir bem os olhos e ouvidos e fechar a boquinha" (PROFESSORA, 2013) para poder entender o que é contado no livro. Esses procedimentos de organização e ordem na sala de aula são retomados em variados momentos, tanto nessa história, como em outras ali trabalhadas. Esses procedimentos nos momentos de leitura de histórias assemelham-se a vários outros mecanismos disciplinares acionados nesse currículo tanto para ensinar a ler, como para ajustar os corpos

172 infantis à cultura escolar. Porém, aqui, eles são considerados necessários para a fruição e apreciação estética da história. Por esse motivo, não há uma rigidez no controle corporal, apesar de haver a exigência do silêncio. Diferentemente do que foi encontrado em outras pesquisas nas quais se analisou os usos da literatura no ensino fundamental, no currículo investigado não foram percebidas ações que visavam a um "[...] controle corporal relacionado à crença de que a 'postura inadequada' promove 'aprendizagens inadequadas'" (ALMEIDA, 2011 , p. 62, destaques da autora). Pelo contrário, parecia operar no currículo investigado, como resultado do encontro dessa prática curricular com o discurso do letramento literário, a ideia de que "[...] as mediações devem favorecer uma maior liberdade para o leitor quando lê literatura, mesmo que a leitura ocorra dentro do ambiente escolar" (ALMEIDA, 2011 , p. 62).

Na leitura da história "Quer brincar de pique-esconde?", além da discussão acerca da postura necessária para ouvir uma história, foram trabalhados também alguns elementos paratextuais considerados importantes e que sempre estavam presentes nas leituras feitas pela professora: o nome do autor/a, ilustrador/a e a função desses/as profissionais na escrita de livros. Em seguida, a professora (2013) inicia a leitura do livro, lendo as quatro 
primeiras páginas: "O macaco brincalhão fazendo palhaçada/ quer brincar de pique-esconde/ com toda bicharada. $\bigcirc$ coelho bem ligeiro/ foi atrás de um coqueiro/ mas, e agora? / Deixou as orelhas de fora".

A professora mostra a imagem do livro e pergunta: "O que acontece se deixar as orelhas de fora?". Pedro Felisberto ${ }^{3}$ responde: "não ouve". A professora continua: "será que é isso? Olha a imagem e vê o que acontece". Gustavo responde "ela acha ele". A professora concorda: "É, ele acha... É pique-esconde, tem que esconder tudo, senão alguém acha ele" (PROFESSORA; ALUNOS, 2013 1. Ela prossegue a narração da história. No processo de interpretação da história narrada, são acionados outros elementos presentes no discurso do letramento literário. Para produzir crianças que sejam não apenas apreciadoras das histórias, mas também capazes de compreendê-las, as leituras e contações de histórias são constantemente interrompidas para que a professora faça perguntas que levem as crianças a construir sentidos para o texto lido. Parece que há aí o entendimento de que "[...] a leitura escolar precisa de acompanhamento porque tem uma direção, um objetivo a cumprir" (COSSON, 2014, p. 62). O discurso pedagógico articulado ao discurso do letramento literário cria como efeito no currículo do primeiro ano a prática de acompanhar a leitura a fim de garantir o pleno entendimento por parte das crianças.

Em função da presença desses dois discursos que operam no currículo do primeiro ano no momento da leitura de histórias, a professora assume a posição de sujeito mediadora da leitura. Nessa posição disponibilizada por esse discurso, a professora "[...] apresenta às crianças um repertório de textos, estabelece contextos e objetivos, informa, faz perguntas que ajudam os alunos a fazerem predições sobre o que determinado texto quer dizer" (KLEIMAN, 2014 , s.p). A professora também aciona a leitura de imagens, algo que é considerado particularmente importante na leitura de textos de literatura infantil já que "[...] o livro infantil se tornou bilíngue, ou seja, a narrativa emerge tanto do texto gráfico quanto das imagens" (ALMEIDA, GOMES, MONTEIRO, 2013, p. 13181 . Assim, sugere-se que as crianças, para interpretar o texto, atentem não somente ao que foi ouvido, mas também às imagens que estão sendo vistas. Para ser uma boa mediadora de leitura, a professora precisa acionar diferentes elementos interpretativos e ajudar os/as alunos/as a perceberem a função deles no processo de compreensão de determinado livro literário. 
As funções atribuídas à professora quando assume a posição de sujeito mediadora de leitura mostram como, em alguns momentos, a literatura funciona como um elemento que provoca conflitos entre os dois dispositivos de poder analisados neste artigo. O dispositivo de antecipação da alfabetização preconiza que as crianças sejam não apenas alfabetizadas, mas também letradas, ou seja, que consigam interpretar os textos lidos. Para isso, esse dispositivo precisa apagar certas marcas consideradas infantis (como a falta de lógica e de racionalidade) para que as crianças aprendam a operar dentro do sistema de regras escolares e da interpretação de textos. Elas devem, assim, deixar de lado algumas das características atribuídas aos/às infantis, como a interpretação literal de situações, algo sugerido pela fala de Pedro Felisberto ao afirmar que, se deixar a orelha de fora, fica-se surdo. Ao mesmo tempo, o discurso do letramento literário articula-se ao dispositivo de infantilidade, reconhecendo a importância de que alguns elementos, como o desenho, sejam trazidos para esse currículo a fim de garantir tanto a interpretação adequada, como a ludicidade e a espontaneidade infantis.

A prática de trazer histórias ilustradas e também de proporcionar leituras que as crianças sejam capazes de realizar antes de estarem alfabetizadas 174 faz com que livros de imagens sejam trabalhados em sala de aula. Os livros de imagens consistem em um gênero textual "[...] comumente apontado como livro para crianças que ainda não sabem ler, já que sua narrativa é eminentemente visual" (ARAÚJO; REILY, 201 1, p. 32). Ele é um dos instrumentos utilizados pelo dispositivo de antecipação da alfabetização para efetivar seus objetivos, já que insere as crianças em relações que despertam o seu interesse pela leitura e pela escrita, fazendo com que elas mobilizem seus esforços para compreender os livros e inserir-se na cultura escrita antes mesmo de se alfabetizarem. Esses livros seduzem e inserem as crianças em relações de poder-saber que fazem com que o interesse pelo universo da leitura seja construído nos/as infantis. $\bigcirc$ livro de imagens é também mais um articulador do dispositivo de infantilidade, já que ele aciona a imaginação e o encantamento, comumente associados ao infantil. "A possibilidade de o livro de imagens poder contar uma história, de penetrar no mundo do encantamento, faz o tempo do real e da magia conviverem" (BELMIRO, 2014, s.p), demandando modos de ser infantil que têm a imaginação como uma de suas características.

Nem todos/as os/as infantis, porém, aceitam facilmente a posição de sujeito imaginativo/a ensinada para eles/as por meio da literatura. Por 
serem subjetivados por múltiplos discursos, muitos/as deles/as apegam-se ao chamado real e nem sempre embarcam nas histórias contadas. Assim, quando se conta uma história na qual uma flor conversa, Karen afirma "mas flor não conversa". Para garantir essa posição de sujeito imaginativa necessária tanto para a literatura como para o dispositivo da infantilidade, ensina-se: "Ah, na história pode tudo! Porque quem escreve usa o quê? Imaginação. E na nossa imaginação tudo pode?" (PROFESSORA; ALUNOS, 2013). A maioria concorda. Porém, quando se afirma que "Se o Luiz quiser escrever, inventar uma história que ele voa, que ele sobe na parede [...]", Kavan interrompe e, acionando saberes aprendidos na mídia, se contrapõe afirmando que, nesse caso, "ele seria o homem-aranha". Ao acionar a imaginação, o diálogo acerca de uma obra literária permite também que outros saberes emerjam, possibilitando relações que, de modo geral, são silenciadas no currículo investigado.

$\bigcirc$ ato de ouvir histórias quase diariamente também despertava muitas emoções nas crianças. Talvez porque, como argumenta Compagnon (2012), a literatura tem a capacidade de provocar "[...] minha compaixão; quando leio eu me identifico com os outros e sou afetado por seu destino; suas felicidades e seus sofrimentos são momentameamente meus" (COMPAGNON, 2012, p. 62). Isso era perceptível na sala de aula quando histórias eram contadas. $\bigcirc$ medo de que algo acontecesse com algum personagem, a preocupação quanto ao destino de outro, a alegria quando a história terminava em final feliz, a curiosidade para descobrir algum mistério mobilizavam as crianças da sala de aula, despertando nelas o interesse pelos livros lidos. Quando - lobo mau ataca a Chapeuzinho cor de abóbora, no livro "Chapeuzinhos coloridos" (TORERO; PIMENTA, 2010), Adryan se preocupa e diz: "Ai, minha nossa senhora, de novo não" (ALUNO ADRYAN, 2013). No momento em que aparece uma assombração no livro "Sete histórias para sacudir o esqueleto" (LAGO, 2002), Fernando diz que o personagem é muito medroso porque ele foge em vez de enfrentar o fantasma. A professora questiona: "Você ia ficar?". O menino diz: "la. la cortar ele na faca" (ALUNO FERNANDO, 2013). O clima construído pela professora também contribuía para que as crianças se envolvessem com as histórias. Assim, no livro "O mistério da caixa vermelha" (PATERNO, s/d) a professora começa a história dizendo: "Tem um mistério aqui". Uma criança indaga, curiosa: An!?! (interjeição de espanto). A professora continua: "Vamos descobrir qual é o mistério?". As crianças respondem em uníssono: "Vamos" (PROFESSORA; ALUNOS, 2013). 
encantamento e a emoção despertados fazem não somente com que as crianças se empolguem e emocionem com as histórias, mas desperta também o desejo de contarem suas próprias histórias. Assim, quando a professora conta a história "O pintinho de Lelé" (MENEZES, s/d), Gustavo fala: "Professora, eu posso falar uma coisa? Eu sei uma história. Eu queria contar hoje". A princípio, a professora hesita, mas muda de ideia e deixa o menino falar. Ele vai para a frente da sala e a professora o ajuda a subir em uma cadeira. Ela comenta com uma das pesquisadoras: "uh, olha o coração dele, ta assim, oh: batendo, batendo!". O menino fica tímido, a princípio, mas, em seguida, começa a contar a história aprendida:

Era uma vez, o coelho e o seu macaco... Aí o coelho falou assim: oh seu macaco... Seu macaco, eu sei onde tem um lugar cheio de amendoim. Os dois vão procurar amendoim e o coelho pega $\circ$ amendoim do seu macaco e sai correndo. E é por isso que o coetho está correndo até hoje do macaco. Fim (ALUNO GUSTAVO, 2013).

A escuta cotidiana de histórias desperta nas crianças o interesse de contar suas próprias histórias, trazendo para o ambiente escolar aquilo que ouviram e conheceram em outros espaços. Tem-se, assim, uma possibilidade de conexão explícita entre o fora e o dentro da escola, entre o currículo e outras vivências das crianças. $\bigcirc$ trabalho com literatura possibilita a emergência de outras histórias além daquelas planejadas pela docente no currículo escolar. Considerando que a contação de histórias "[...] é uma arte que pode ser desenvolvida por qualquer pessoa que aprecia narrativas, que queira se envolver com elas e que tenha voz e memória" (GROSSI, 2014 , s.p.), o currículo parece, no encontro entre o dispositivo de infantilidade e da antecipação da alfabetização, produzir a posição de sujeito criança contadora de histórias. Porém, asssim como "um leitor vive mil vidas antes de morrer" (MARTIN, 2006, p. 584), um currículo que trabalha com a literatura também disponibiliza múltiplas posições de sujeito a serem vividas pelos/as alunos/as e professoras. São as posições de sujeito disponibilizadas quando a literatura é utilizada para trabalhar diferentes disciplinas escolares que serão analisadas no próximo tópico. 


\section{A literatura infantil e o trabalho com as disciplinas escolares}

No currículo investigado em que opera o dispositivo de antecipação da alfabetização, muitas vezes, há um predomínio de saberes e conhecimentos relativos ao "ensinar a ler e escrever" que faz com que saberes de outras disciplinas escolares sejam deixados de lado. Em variados momentos, o predomínio das atividades de alfabetização fazia com que saberes ligados à Geografia, História e Ciências fossem trabalhados de forma menos intensa ou que as atividades a eles relacionadas se caracterizassem mais como atividades de alfabetização. Parece que essa ideia também aparece quando se utiliza a literatura para introduzir algum assunto relativo a essas disciplinas escolares. $\bigcirc$ caráter multifacetado da literatura, todavia, faz com que outras possibilidades apareçam nesse currículo.

Para introduzir o assunto "Brinquedos e brincadeiras", um dos temas do Projeto "O mundo ao meu redor" utilizado para trabalhar Geo-História na escola, a professora conta a história "O tempo da vovó" (DIÁRIO DE CAMPO, 20131 . Em seguida, dá como para-casa uma atividade que consiste em entrevistar pais e avós para conhecer as brincadeiras preferidas deles. No dia seguinte, ela pede que Fernando faça o reconto da história. $\bigcirc$ menino relembra, com a ajuda de outras crianças, as brincadeiras que a avó da história brincava: polícia e ladrão, rouba-bandeira, peteca. Relacionam a história lida com o que os avós e pais falaram sobre as brincadeiras do passado. Ao final, Fernando diz para Lucas: "a gente podia brincar de polícia e ladrão no recreio, né". Lucas concorda e chama outros colegas (PROFESSORA; ALUNOS, 2013). Nesse currículo, o uso da literatura articula os saberes relativos à alfabetização aos saberes das outras disciplinas escolares. De modo semelhante, esse livro também se articula ao dispostivo de infantilidade que ensina que "criança gosta de brincar" e que "brincadeira é algo da vida infantil". Afinal, avós e pais brincaram quando eram crianças e, ao suscitar essa discussão, o currículo proporciona que as crianças conheçam brincadeiras de outros tempos, fazendo com que sejam infantis-brincantes. Nesse processo, garante-se a perpetuação de certos elementos da chamada "cultura da infância" (SARMENTO, 2005), transmitidos de geração em geração por meio da articulação do dispositivo de infantilidade com o dispositivo de antecipação da alfabetização, mobilizados pela literatura infantil. 
Para trabalhar os animais, a professora também utiliza uma história: "Corpo de gente e corpo de bicho" (MANNING; GRANSTROM). Ela inicia explicando: "Quem escreveu esse livro foi o Mick Hannigan e Britta Granstorm. Vamos lá, gente!" E começa a narrar a história:

Olhe no espelho. De que cor são seus olhos? Castanhos, azuis, verdes... Os olhos deixam a gente ver o mundo. Feche os olhos. Como é a sensação de não ver mais? Os olhos da lula gigante são grandes do tamanho de uma bola de futebol. Olha a lula gigante (DIÁRIO DE CAMPO, 2013).

As crianças se espantam com o tamanho dos olhos e com outras informações a respeito dos animais narrados. A história prossegue com informações sobre a audição, o olfato, o cérebro, os músculos e ossos de diversos animais. O livro traz também alguns comandos a serem executados pelo/a leitor/a e, posteriormente, comparados com as informações do livro. Dessa maneira, em certo momento, pede-se: "Gritem bem alto!" As crianças gritam. "O ar fez as suas cordas vocais vibrarem. Agora, falem bem baixinho." As crianças fazem barulhos, nem sempre tão baixinhos quanto sugere o livro (PROFESSORA;

178 ALUNOS, 20131.

Ao trazer para a sala de aula comandos a serem executados pelos/ as alunos/as, o livro "Corpo de gente e corpo de bicho" gera um conflito com uma das características do dispositivo de antecipação da alfabetização que preconiza que, para aprender a ler e a escrever, é preciso inserir-se nas regras disciplinares da escola. Ela entra em conflito com esse dispositivo, na medida em que proporciona nesse currículo a vivência de atitudes e comportamentos geralmente negados. Por meio dela, é possível escapar à disciplina e viver outras experiências. Nem sempre, porém, isso é feito de forma efetiva. Em outro momento, sugere-se no mesmo livro:

'Agora, pulem'. A professora sugere: 'pode dar um pulinho e voltar pro lugar. Um pulinho só e voltar. Voltou pro lugar. Voltou pro lugar, Luiz! Luiz, ouve, ouve! Senta de novo! Suas pernas têm ossos e músculos fortes que ajudam vocês a andar, saltar, pular e correr' (PROFESSORA, 2013).

Se, em certo momento, a literatura possibilita o escape às normas, em outro, o modo como ela é trabalhada limita essas vivências, subordinando-a 
ao dispositivo de antecipação da alfabetização. Essa limitação não é vivida, porém, sem conflitos. Quando a literatura é escolarizada de maneira a ensinar determinados saberes, as crianças, várias vezes, protestam contra essa prática. Quando termina de contar a história "Corpo de gente e corpo de bicho", a professora diz: "Eu vou dar uma atividade rapidão". Lucas se opõe: "ah, não, professora, faz brincadeira." Ainda assim, a atividade é realizada. Quando, após contar a história "Zeropeia" (SOUZA, 1999), pede-se que uma ilustração seja feita, Karen protesta: "Ah, nem! De novo!" (PROFESSORA; ALUNOS, 2013).

Esse modo de usar a literatura na sala de aula diferencia-se daquele analisado no tópico anterior, já que aqui o texto literário é utilizado como pretexto (LAJOLO, 2009) para trabalhar determinado conteúdo. Esse aspecto vai ser criticado pelo discurso do letramento literário por ser considerado o operador de uma "inadequada escolarização da literatura" (SOARES, 1999, 25). De modo geral, essa escolarização inadequada é apontada quando se utilizam textos literários "para ensinar gramática ou inculcar valores morais" (LAJOLO, 2009, p. 103). No currículo investigado, não se procurava ensinar gramática, mas a literatura foi, algumas vezes, pretexto para trabalhar saberes de diversas disciplinas escolares.

Nesse processo, ela também possibilitava que outros temas estivessem presentes no currículo, mesmo quando se pressupõe sua escolarização com fins didáticos. Quando se trabalha, por exemplo, o tema "Família" em Geo-história, outras discussões, vinculadas às vivências infantis, aparecem. Ao contar a história "O mistério da mamãe" (RIGUEIRA; TEIXEIRA, s/d) as crianças trazem exemplos de suas famílias que constroem outras relações em sala de aula. Kaio conta do seu irmão que nasceu. A professora relata que, quando seu irmão mais novo nasceu, ela ficou com ciúmes. Mas aproveita para ensinar que a mãe"vai gostar [de você] do mesmo jeito. Mas às vezes, Kaio, ela vai precisar dar uma atenção diferente para o bebê". Gustavo também ajuda, dizendo que a mãe "vai precisar da ajuda da gente". A professora concorda e complementa: "Kaio, você vai ter que ajudar com as fraldas. $\bigcirc$ pai também vai participar da troca. Ajudar a tomar banho, a trocar fralda... Bebê sabe falar? Avisar à mamãe quando o bebê estiver acordado, chorando. Pajear o sono do bebê. Quando ele quiser mamadeira" (PROFESSORA; ALUNOS, 2013).

Ao trazer um tema do cotidiano infantil para a sala de aula, por meio da literatura, as situações e dramas infantis, como o ciúme pelo nascimento de 
um irmão, aparecem no currículo escolar. A literatura infantil assume outra de suas funções, qual seja: "[...] se tornar espaço para a criança refletir sobre sua condição pessoal" (ZILBERMAN, 2009, p. 24). $\bigcirc$ dispositivo de infantilidade é acionado nesse momento para garantir que certo modo de viver a infância seja possibilitado, modo esse que preconiza a alegria e a vivência familiar sem conflitos como importantes. $O$ trabalho com família também se relaciona ao terceiro modo como a literatura está presente nesse currículo: o trabalho com a diversidade. Esses modos serão explorados no próximo tópico, já que as possibilidades com a literatura são variadas no currículo escolar. Sendo assim, encerra-se este tópico com a musiquinha tantas vezes cantada pela professora ao finalizar a leitura de um dos livros e que já incitava para a possibilidade de sempre contar novas histórias no currículo escolar: "[...] essa história, entrou por uma porta e saiu pela outra, quem não gostou que conte outra" (PROFESSORA, 20131.

\section{Diversidade e literatura: preceitos morais no currículo do primeiro ano}

Famílias com organizações diversas, grupos étnicos minoritários, diferenças e discriminações de gênero e sexualidade, questões relativas às deficiências, aspectos característicos de diferentes grupos geracionais: essas são algumas das temáticas que, nos últimos anos, têm emergido na literatura infantil. Desde sua invenção, a literatura infantil tem servido para ensinar determinados comportamentos aos/às alunos/as nas escolas. A vinculação com o ensino e com a infância, porém, faz com que, algumas vezes, à literatura infantil sejam "[...] imputadas [...] as qualidades atribuídas à infância em geral, quais sejam: a menoridade, a inferioridade e o estágio de 'ainda não' literatura" (ZILBERMAN, 2009, p. 52). Por ter um público direcionado e por, às vezes, ser utilizada para fins didáticos, "[...] a literatura infantil, desde seu princípio, empreende uma luta para ser autorizada como literatura" (FREITAS, 2014 , p. 35). Apesar dessa luta, na atualidade continua havendo um trabalho com a literatura que visa ao ensino de determinados valores morais. Ela tem sido acionada para trabalhar as temáticas relativas à diversidade na sala de aula, tendo se mostrado particularmente fecunda para trabalhar essas questões com as crianças. 
No currículo analisado, alguns dos livros lidos abordavam a dimensão da diversidade ou suscitavam discussões que faziam com que esses temas aparecessem na sala de aula. É o que acontece com a temática "família". Sobre esse assunto, foram contadas as histórias dos livros "Um amor de família" (ZIRALDO, 1991), "O mistério da mamãe" e "Tudo bem ser diferente" (PARR, 2002), além de outras em que apareciam famílias. Em quase todas elas, o modelo familiar presente era o da família nuclear e heterossexual. Aparentemente, a única "perturbação" a esse modelo familiar refere-se ao livro "Tudo bem ser diferente". Em certo momento do livro, ensina-se: "Tudo bem ter mães diferentes. Tudo bem ter pais diferentes".

Ao ler essa história, a professora transformou as afirmativas do livro em perguntas que as crianças iam respondendo. Assim, a afirmação "Tudo bem ter mães diferentes. Tudo bem ter pais diferentes" foi transformada em perguntas, as quais as crianças responderam afirmativamente. A professora exemplificou essa diferença, dizendo: "Eu sou mais alta que o meu marido. Nós somos diferentes". As crianças fizeram vários comentários relativos à altura. A história continua dizendo: "Tudo bem ser adotado". Nesse momento, Kaio protesta dizendo que não está tudo bem em ser adotado. Gustavo explica que não está tudo bem "porque a gente gosta da mãe e do pai!". A docente diz: "Ah! Não estou falando do seu caso não, porque o seu pai e a sua mãe puderam cuidar de você. Mas e uma criança que o pai e a mãe deles não puderam cuidar deles, aí uma mamãe e um papai, ou uma mãe só, ou dois papais ou duas mamães, resolveram adotar aquela criança com muito carinho, tudo bem?" As crianças concordam que, nesse caso, está tudo bem. As diferentes organizações familiares sugeridas pela docente não são comentadas pelas crianças (PROFESSORA; ALUNOS, 2013).

Parece que, no comentário suscitado pelo livro lido, a temática da homossexualidade é tratada de forma naturalizada e apenas como uma entre várias possibilidades de família. Silveira e Kaercher (2013), ao analisarem livros de literatura infantil que tratam explicitamente de organizações de famílias homoparentais, notaram que, de modo geral, esses livros tratam a temática de forma "coloquial", focando na felicidade das crianças que convivem nessas famílias em vez de aludirem a questões como direitos ou movimento LGBT. Há, assim, uma aproximação do modo como a literatura tem tratado a questão da diversidade cultural com formas de multiculturalismo liberal-humanista (SILVA, 2001 1, nas quais a diversidade é celebrada em vez de problematizada. Tratar 
a diversidade, dessa forma, faz com que "os outros", ou seja, aqueles/as que não estão no centro das relações de poder, sejam vistos ora como "[...] alguém a tolerar" (DUSCGATZKY; SKLIAR, 2011 , p. 121 e 127), ora como "[...] um sujeito pleno de um grupo cultural".

Na primeira perspectiva, ao despolitizar a diferença e colocar a discussão em termos de "respeito e tolerância", ensina-se que os outros existem, mas não se explica como eles se tornaram "outros" e porque é preciso que suas diferenças sejam aceitas na sociedade atual. Ao apresentar variadas diferenças e afirmar que não existe nenhum problema com elas, o livro "Tudo bem ser diferente" as iguala e não propõe uma problematização para se entender o que fez com que, em algum momento, essas diferenças fossem consideradas como algo inadequado. Já na perspectiva do "[... ] outro como sujeito pleno de um grupo cultural", as diferenças são resultado de padrões existentes em dada cultura e que, por isso, não seria possível modificá-las ao problematizá-las. As diferenças são consideradas "[...] absolutas, textuais, plenas e as identidades se constroem em únicos referenciais" (DUSCGATZKY; SKLIAR, 2011 , p. 127). Novamente, há pouco espaço para problematização e para a discussão das bases de poder que fizeram com que dado grupo fosse considerado diferente.

182 A opção por tratar a diversidade dessa forma na literatura e no currículo, talvez se articule ao dispositivo de infantilidade que atua no sentido de proteger as crianças de temas polêmicos.

Entretanto, como as crianças, muitas vezes, escapam a esse dispositivo, em outras situações, elas demonstram ter experiências que vão além daquelas presumidas nos livros e no currículo. Assim, quando em um livro de parlendas (ALMEIDA, 2000) uma delas afirma "O galo e a galinha/foram à festa em Portugal/ o galo foi de saia/e a galinha de avental", Maria afirma "[...] eu tenho um primo que veste de mulher" (ALUNA MARIA, 2013). Ainda que a fala da aluna não tenha maiores repercussões, ela demonstra como as crianças têm saberes que vão além daqueles apresentados nos livros de literatura que operam com a ideia de que seria preciso proteger a infância de determinados temas. Parece circular nesse currículo alguns discursos pedagógicos que marcam os/as infantis como não sendo suficientemente capazes de compreender certos assuntos. Ignora-se isso nesse currículo, que opera de forma "adultocêntrica", no "[...] afã por colocar a infância em um mundo paradisíaco" (SANTOMÉ, 1995, p. 163). Nesse processo, temáticas relevantes no âmbito social e que fazem parte do cotidiano infantil são deixadas de lado. 
Outros temas próximos das vivências infantis, porém, são incluídos nesse currículo por meio dos livros de literatura infantil. É o caso, por exemplo, da presença de personagens avós nesses livros. Fernandes (2013) constata que eles/as estão cada vez mais presentes nos livros de literatura infantil. Além disso, eles/as também estão presentes nas vidas das crianças da turma investigada, pois muitas delas ficavam com seus/suas avós enquanto seus pais e suas mães trabalhavam. Nesse sentido, havia uma divergência no modo como esses eram apresentados nos livros lidos na sala de aula e as avós com que elas tinham contato. Na história "O grande rabanete", o avó e a avô são representados como dois idosos que vivem ao lado de seu neto, sua neta e seus animais de estimação. $\bigcirc$ mesmo ocorre em "O tempo da vovó", sendo acrescido a isso o fato de que nesse caso (como em outros livros de literatura infantil) "[...] a figura do velho aparece como contador de histórias vivenciadas ou inventadas, valorizando a velhice como fonte de sabedoria para as crianças" (FERNANDES, 2013, p. 1111 ).

Esse modo de narrar a velhice, porém, entra em conflito com as avós reais que frequentam o espaço escolar. A avó de Eric, por exemplo, causa estranheza naquele currículo por ser "toda tatuada" (DIÁRIO DE CAMPO, 2013). A avó de Karen é confundida com sua mãe em função de aparentemente ser bastante jovem (DIÁRIO DE CAMPO, 2013). Essas avós fogem ao padrão estabelecido pelo currículo operacionalizado pela literatura infantil. De modo semelhante, a própria ideia de pessoas velhas que circula nesse currículo também não é aceita facilmente pelas crianças. Na história "O sapato de miava" (ORTHOF, 2007), a personagem idosa é chamada de "Dona Velha". Leandra diz: "Dona velha! Que preconceito!" (ALUNA LEANDRA, 2013). Cabe, porém, refletir sobre o motivo pelo qual a menina considera que o fato de chamar alguém de "velha" seja preconceituoso. Talvez ela faça isso em função da emergência que tem acontecido na contemporaneidade de novos termos para se referir às pessoas nessa fase da vida. Em vez de velhos/as, eles/ as passam a ser identificados como idosos/as ou como pertencentes à terceira idade (PEIXOTO, 1995). Esses termos trazem as marcas de um discurso sobre a velhice que diferencia aqueles/as que envelheceram (e que ficaram dependentes fracos, senis) daqueles/as que estão entrando em outra etapa da vida que não trazem marcas negativas, mas que apresentam novas possibilidades. Leandra parece operar com essa lógica ao achar preconceituoso o fato do livro tratar uma personagem como velha. É interessante verificar como um 
discurso que trabalha explicitamente com a diversidade é considerado pelos/ as infantis como preconceituoso.

Talvez isso também ocorra porque a diversidade é tratada nessas histórias como um dado natural e não como uma construção histórica permeada pelas relações de poder. $\bigcirc$ tratamento dado a ela é pouco problematizador. Isso é perceptível na história "Tudo bem ser diferente" em que "diferentes diferenças" são tratadas de forma semelhante. Assim, "usar óculos, ter rodas ou dançar sozinho" são apresentados como diferenças equivalentes, que devem ser tratadas igualmente. Por meio do princípio do respeito, considera-se que "tudo bem" ter tanto características pessoais distintas como fazer parte de grupos etnicorraciais que historicamente gozam de menos prestígio na sociedade. Não há problema em ter essas diferenças, mas também não há discussões mais aprofundadas sobre as situações de desigualdade existentes.

Por meio dos livros de literatura infantil disponibilizados nesse currículo, ensina-se que as crianças devem "respeitar a diferença". Estabelece-se a norma de que as crianças devem respeitar os outros e serem respeitadas. Os livros de literatura são usados como um "[...] dos instrumentos que têm servido à multiplicação da norma em vigor" (ZILBERMAN, 2009, p. 23). Considerando

184 que "[...] a experiência e o exemplo guiam a conduta melhor do que as regras" (COMPAGNON, 2012, p. 39), os livros infantis buscam as cores, as trocas divertidas, os jogos com palavras para governar condutas infantis de maneira que eles/as aprendam o respeito pelos diferentes. A literatura é considerada um artefato que, "[...] em movimentos de ajustes sutis e constantes, tanto gera comportamentos, sentimentos e atitudes, quanto, prevendo-os, dirige-os, reforça-os, matiza-os, atenua-os; pode revertê-los, alterá-los" (LAJOLO, 1993, p. 26). Esse artefato é convocado, então, para ensinar como lidar com a diferença, sem problematizá-la, mas também sem discriminá-la. Ocorre, portanto, uma atualização do caráter moralizante da literatura infantil. Se, no passado, ela era acionada para construir o amor pela pátria, a obediência aos mais velhos e o apreço pelo mundo adulto, hoje, ela é convocada para governar infantis para que, desde o início de sua escolarização, aprendam a respeitar as diferenças e conviver com elas, amenizando conflitos e construindo modos de ser e estar no mundo.

Em síntese, é possível perceber como, no currículo analisado, a literatura se articulava ou disputava espaço com os dois dispositivos aqui analisados, produzindo infantis que tinham marcas distintas. Essas marcas, às vezes, iam 
na mesma direção, mantendo certas características construídas na Modernida pelo dispositivo de infantilidade. Em outros momentos, iam em sentidos opostos, atuando na produção de um/a infantil que precisa se alfabetizar e letrar o quanto antes. Isso gerava conflitos tanto no currículo escolar, como nas posições de sujeito demandadas. A literatura aparecia também como campo fértil para transgressões e modos de pensar distintos daqueles engendrados pelos dispositivos de infantilidade e de antecipação da alfabetização. Assim, a literatura infantil disponibilizava diferentes vivências e posições de sujeito para os/as infantis. Ela deixava marcas nos modos de ser de professora e alunos/ as no currículo investigado, como se procurou demonstrar aqui. Afinal, como ensinava outra musiquinha cantada pela professora ao término de cada história: "[...] a historinha divertida que acabamos de ouvir, vai entrar em nossas vidas, quem quiser pode aplaudir" (PROFESSORA, 2013).

\section{Notas}

1 Não é objetivo deste artigo discutir o que é a literatura infantil. Para isso, sugere-se a leitura de Soares (1999) e Zilberman (2009).

2 Esse dispositivo atua para, inclusive, garantir que crianças sejam alfabetizadas desde a educação infantil.

3 Respeitando as regras do Comitê de Ética na Pesquisa e os acordos feitos com os/as pesquisados/as, todos os nomes aqui utilizados são fictícios.

\section{Referências}

ALMEIDA, Theodora. Quem canta seus males espanta 2. ed. São Paulo: Caramelo, 2000. ALMEIDA, Eliana Guimarães. O livro de literatura infantil no primeiro ciclo: um estudo sobre a mediação escolar da literatura em um contexto socioeconomicamente desfavorecido. 2011 . 138f. Dissertação (Mestrado em Educação) - Programa de Pós-Graduação Conhecimento e Inclusão Social em Educação. Universidade Federal de Minas Gerais, Belo Horizonte, 2011.

ALMEIDA, Tatyane; GOMES, Maria de Fátima; MONTEIRO, Sara. Aprendizagem e desenvolvimento de crianças de seis anos na Roda de História. Educação e Realidade, Porto Alegre, v. 38, n. 4, p. 1303-1326, out./dez. 2013.

ALUNA LEANDRA. Diário de campo. Belo Horizonte (MG), 28 ago. 2013. 
ALUNA MARIA. Diário de campo. Belo Horizonte (MG), $1^{\circ}$ ago. 2013.

ALUNO ADRYAN. Diário de campo. Belo Horizonte (MG), 7 nov. 2013.

ALUNO FERNANDO. Diário de campo. Belo Horizonte (MG), 25 out. 2013.

ALUNO GUSTAVO. Diário de campo. Belo Horizonte (MG), 2 maio 2013.

ARAÚJO, Hanna; REILY, Lúcia. Livro de Imagem: três artistas narram seus processos de criação de narrativas visuais. Cultura Visual, Salvador, n. 15, p. 31-47. maio 2011.

BELMIRO, Célia. Livro de imagens. Glossário Ceale: termos de alfabetização, leitura e escrita para educadores. Belo Horizonte, 2014. Disponível em: <http://ceale.fae.ufmg. br/app/webroot/glossarioceale/verbetes/livro-de-imagens.> Acesso em: 22 jun. 2015.

BRAGANÇA, Angiolina. CARPANEDA, Isabella. Quer brincar de pique-esconde? São Paulo: FTD, 2008.

CALDEIRA, Teresa. A presença do autor e a pós-modernidade em antropologia. Novos estudos CEBRAP, São Paulo, n. 21, p. 133-157, jul. 1988.

CLIFFORD, James. A experiência etnográfica: antropologia e literatura no século XX. Rio de Janeiro: Editora UFRJ, 2008.

COMPAGNON, Antoine. Literatura para quê. Tradução Laura Taddei Brandini. Belo Horizonte: Editora UFMG, 2012.

COSSON, Rildo. Letramento literário: teoria e prática. São Paulo: Contexto, 2014.

DELEUZE, Gilles. Controle e devir. In: DELEUZE, Gilles. Conversações - 1972-1990. Tradução Peter Pal Pelbart. São Paulo: Editora 34, 1992.

DIÁRIO de campo. Belo Horizonte (MG). 25 abr. 2013.

DIÁRIO de campo. Belo Horizonte (MG). 28 abr. 2013.

DIÁRIO de campo. Belo Horizonte (MG). 30 maio 2013.

DIÁRIO de campo. Belo Horizonte (MG). 21 jun. 2013.

DIÁRIO de campo. Belo Horizonte (MG). 28 jun. 2013.

DIÁRIO de campo. Belo Horizonte (MG). 29 jun. 2013.

DIÁRIO de campo. Belo Horizonte (MG). 3 jul. 2013. 
DIÁRIO de campo. Belo Horizonte (MG). 2 ago. 2013.

DIÁRIO de campo. Belo Horizonte (MG). 5 dez. 2013.

DUSCGATZKY, Silvia; SKLIAR, Carlos. O nome dos outros. Narrando a alteridade na cultura e na educação. In: LARROSA, Jorge; SKLIAR, Carlos (Org.) Habitantes de Babel. Belo Horizonte: Autêntica, 2011.

FERNANDES, Célia Regina. Avós e netos na literatura infantil: vidas compartilhadas. Educação e Realidade, Porto Alegre,v. 38, n. 4, p. 1089-1 1 12, out./dez. 2013.

FOUCAULT, Michel. A vida dos homens infames. In: FOUCAULT, Michel. Ditos e escritos I: problematização do sujeito. Tradução Vera Lúcia Ribeiro. Rio de Janeiro: Forense, 2006.

FOUCAULT, Michel. Linguagem e literatura. In: MACHADO, Roberto. Foucault, a filosofia e a literatura. Tradução Roberto Machado. Rio de Janeiro: Jorge Zahar, 2001.

FOUCAULT, Michel. O anti-édipo: uma introdução à vida não fascista. In: ESCOBAR, Carlos Enrique (Org.) Dossiê Deleuze. Rio de Janeiro: Holon Editorial, 1991.

FOUCAULT, Michel. Sobre a história da sexualidade. In: MACHADO, Roberto. Microfísica do poder. Tradução Roberto Machado. Rio de Janeiro: Graal, 2000.

FREITAS, Daniela. Literatura infantil dos kits de literatura afro-brasileira da PBH: um currículo para ressignificação das relações étnico-raciais? 2014. 280f. Tese (Doutorado em Educação) - Programa de Pós-Graduação Conhecimento e Inclusão Social em Educação. Universidade Federal de Minas Gerais, Belo Horizonte, 2014.

GEERTZ, Clifford. A interpretação das culturas. Rio de Janeiro: LTC, 1989.

GROSSI, Maria Elisa. Contação de histórias. Glossário Ceale: termos de alfabetização, leitura e escrita para educadores. Belo Horizonte, 2014. Disponível em: <http://ceale.fae. ufmg.br/app/webroot/glossarioceale/verbetes/contacao-de-historias> Acesso em: 22 jun. 2015.

KLEIMAN, Angela. Compreensão leitora. Glossário Ceale: termos de alfabetização, leitura e escrita para educadores. Belo Horizonte, 2014. Disponível em: <htp://ceale.fae.ufmg.br/ app/webroot/glossarioceale/verbetes/compreensao-leitora>. Acesso em: 22 jun. 2015.

LAGO, Angela. Sete histórias de sacudir o esqueleto. São Paulo: Companhia das Letras, $\mathrm{s} / \mathrm{d}$.

LAJOLO, Marisa. Do mundo da leitura para a leitura do mundo. São Paulo: Ática, 1993. 
LAJOLO, Marisa. O texto não é pretexto. Será que não é mesmo ?. In: ZILBERMAN, Regina; ROSING, Tania (Org.). Escola e leitura: Velha crise - Novas alternativas. São Paulo: Global, 2009

LARROSA, Jorge. Pedagogia profana: danças, piruetas e mascaradas. Tradução Alfredo Veiga-Neto. Porto Alegre: Contrabando, 1998.

MACHADO, Roberto. Foucault, a filosofia e a literatura. Rio de Janeiro: Jorge Zahar, 2001. MANNING, Mick; GRANSTROM, Brita. Corpo de gente e corpo de bicho. São Paulo: Atica, 2004.

MENEZES, Silvana. O pintinho de Lelé. Belo Horizonte: Editora Abacatte, s/d.

PAIVA, Aparecida; PAULINO, Graça. PASSOS, Marta. Literatura e leitura literária na formação escolar. Belo Horizonte: Ceale, 2006.

ORTHOF, Sylvia. O sapato de miava. São Paulo: FTD, 2007.

PARR, Todd. Tudo bem ser diferente. São Paulo: Panda Books, 2002.

PATERNO, Semiramis. O mistério da caixa vermelha. Belo Horizonte: Editora Lê, s/d.

PAULINO, Graça. Letramento Literário: cânones estéticos e cânones escolares. In: ROSA, Cristina (Org.). Das leituras ao letramento literário. Pelotas: EDGUFPel, 2010.

PEIXOTO, Clarice. Entre o estigma e a compaixão e os termos classificatórios: velho, velhote, idoso, terceira idade. In: BARROS, Miryam (Org.). Velhice ou terceira idade? Estudos antropológicos sobre identidade, memória e política. Rio de Janeiro: Fundação Getúlio Vargas, 1995.

PROFESSORA. Diário de campo. Belo Horizonte (MG), 28/06/2013.

PROFESSORA. Diário de campo. Belo Horizonte (MG), 29/06/2013.

PROFESSORA; ALUNOS. Diário de campo. Belo Horizonte (MG), 4 maio 2013.

PROFESSORA; ALUNOS. Diário de campo. Belo Horizonte (MG), 2 maio 2013.

PROFESSORA; ALUNOS. Diário de campo. Belo Horizonte (MG), 2 ago. 2013.

PROFESSORA; ALUNOS. Diário de campo. Belo Horizonte (MG), 4 maio 2013.

PROFESSORA; ALUNOS. Diário de campo. Belo Horizonte (MG), 4 jun. 2013. 
PROFESSORA; ALUNOS. Diário de campo. Belo Horizonte (MG), 22 jun. 2013.

PROFESSORA; ALUNOS. Diário de campo. Belo Horizonte (MG), 27 abr. 2013.

PROFESSORA; ALUNOS. Diário de campo. Belo Horizonte (MG), 28 jun. 2013.

PROFESSORA; ALUNOS. Diário de campo. Belo Horizonte (MG), 28 ago. 2013.

PROFESSORA; ALUNOS. Diário de campo. Belo Horizonte (MG), 29 jun. 2013.

PROFESSORA; ALUNOS. Diário de campo. Belo Horizonte (MG), 29 jun. 2013.

RIGUEIRA, Luciana; TEIXEIRA, Elisabeth. O mistério da mamãe. São Paulo: Paulinas, s/d.

SANTOMÉ, Jurjo. As culturas negadas e silenciadas no currículo escolar. In: SILVA, Tomaz Tadeu da. Alienígenas na sala de aula: uma introdução aos Estudos Culturais em Educação. Petrópolis: Vozes, 1995.

SARMENTO, Manuel. Gerações e alteridade: interrogações a partir da sociologia da infância. Educação e Sociedade, Campinas, v. 26, n. 91, p. 361-378, maio/ago. 2005.

SILVA, Tomaz Tadeu da. Documentos de identidade: uma introdução às teorias do currículo. Belo Horizonte: Autêntica, 2001.

SILVEIRA, Rosa. Leitura, literatura e currículo. In: COSTA, Marisa (Org.) O currículo nos limia-

res do contemporâneo. Rio de Janeiro: DP\&A, 2005.

SILVEIRA, Rosa; KAERCHER, Gládis. Dois papais, duas mamães: novas famílias na literatura infantil. Educação e Realidade, Porto Alegre, v. 38, n. 4, p. 1089-1 1 12, out./dez. 2013.

SOARES, Magda Becker. A escolarização da Literatura Infantil e Juvenil. In: EVANGELISTA, Aracy; BRANDÃO, Heliana; MACHADO, Maria Zélia (Org.). A Escolarização da Literatura: o Jogo do Livro Infantil e Juvenil. Belo Horizonte: Autêntica, 1999.

SOARES, Magda Becker. Alfabetização e literatura. Guia da alfabetização. Educação, São Paulo, v. 2, p. 12-29, 2010.

SOUZA, Herbet de. Zeropeia. São Paulo: Editora Salamandra, 1999.

TORERO, José; PIMENTA, Marcus. Chapeuzinhos coloridos. Rio de Janeiro: Objetiva, 2010. ZILBERMAN, Regina. A literatura infantil na escola. São Paulo: Gaudi Editorial, 2009.

ZIRALDO. Um amor de família. São Paulo: Melhoramentos, 1991. 
Profa. Dra. Maria Carolina da Silva Caldeira Universidade Federal de Minas Gerais Centro Pedagógico da Escola de Educação Básica e Profissional | UFMG Grupo de Estudos e Pesquisas em Currículo e Culturas da Faculdade de Educação |FaE | UFMG

E-mail | mariacarolinasilva@hotmail.com

Profa. Dra. Marlucy Alves Paraíso Universiade Federal de Minas Gerais Faculdade de Educação Departamento de Administração Escolar Programa de Pós-Graduação em Educação Fundadora e Coordenadora do Grupo de Estudos e Pesquisas em Currículos e Pesquisadora Produtividade 1D do CNPQ E-mail | marlucyparaiso@gmail.com

Recebido 17 out. 2015 Aceito $1^{\circ}$ mar. 2016 